\title{
Development of Resistance Welding for Silicon Carbide
}

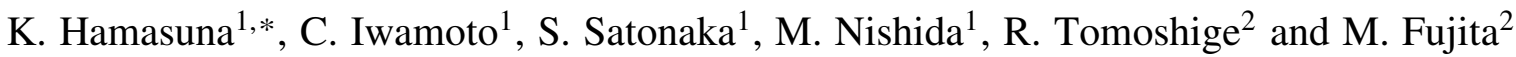 \\ ${ }^{1}$ Graduate School of Science and Technology, Kumamoto University, Kumamoto 860-8555, Japan \\ ${ }^{2}$ Sojo University, Kumamoto 860-8691, Japan
}

Resistance welding was applied to the bonding of SiC to metals. The welded interface structure was observed by high-resolution transmission electron microscopy to reveal the reaction during welding. The maximum bonding temperature of $\mathrm{SiC}$ varied with the rate of welding current rise. At the welded interface, $\mathrm{Al}_{4} \mathrm{C}_{3}, \mathrm{Al}$ and an amorphous phase were formed adjacent to $\mathrm{SiC}$ in the $\mathrm{SiC} / \mathrm{Al}$ system. The $\mathrm{SiC} / \mathrm{Al}$ interface was flat at the atomic level and the crystallographic orientation relationship between $\mathrm{SiC}$ and $\mathrm{Al}$ was observed. For the $\mathrm{SiC} / \mathrm{Ag}$-Cu-Ti alloy system, the reaction phases $\mathrm{TiC}$ and $\mathrm{Ti}_{5} \mathrm{Si}_{3}$ were formed at the interface. The thickness of the reaction phases varied with the rate of welding current rise, and, under specific welding conditions, Ag formed directly adjacent to SiC without the reaction phases. [doi:10.2320/matertrans.48.1060]

(Received August 4, 2006; Accepted February 23, 2007; Published April 25, 2007)

Keywords: resistance welding, $\mathrm{SiC}$, high-resolution transmission electron microscopy, aluminum, interface

\section{Introduction}

Silicon carbide has excellent thermal and mechanical properties, and its application is further extended with the development of new bonding techniques. Brazing and diffusion bonding are typical effective methods of bonding $\mathrm{SiC}$ and metals, and have been widely used because of their productivity and reliability. However, they require a long bonding time, and during bonding, the atmosphere should be controlled to prevent oxidation. Thus, in this study, we applied resistance welding, which takes only a few seconds for bonding and is mainly used in the field of the metal bonding, for bonding $\mathrm{SiC}$ to metals.

The welding systems used were $\mathrm{SiC} / \mathrm{Al}$ and $\mathrm{SiC} / \mathrm{Ag}-\mathrm{Cu}-$ Ti. The bonding processes of these systems have been widely studied at the atomic level. In the $\mathrm{SiC} / \mathrm{Al}$ system bonded by solid state bonding, a thin amorphous phase is observed at the interface and the formation of the amorphous phase is discussed on the basis of thermodynamic and kinetic considerations. ${ }^{1)}$ In contrast, in the $\mathrm{SiC} / \mathrm{Al}$ system bonded with molten $\mathrm{Al}$, the reaction phase $\mathrm{Al}_{4} \mathrm{C}_{3}$ is formed. $^{2,3)}$ In previous reports, ${ }^{1-3)}$ the analysis of the interface microstructure has been suggested to be important, because the morphology of the interface varies depending on the bonding process. In the $\mathrm{SiC} / \mathrm{Ag}-\mathrm{Cu}-\mathrm{Ti}$ system, in addition to the atomic structure observation of the interface, the reaction between $\mathrm{SiC}$ and molten $\mathrm{Ag}-\mathrm{Cu}-\mathrm{Ti}$ alloy is directly clarified in situ at the atomic level. Moreover, SiC dissociation and the nucleation and growth of the reaction phase TiC are dynamically observed. ${ }^{4-6)}$ However, the resistance welding processes of the above systems have not been reported so far.

In this study, the welded interface produced by resistance welding was observed using a high-resolution transmission electron microscope (HRTEM) to understand the bonding process of the resistance welding, and was compared with that produced by other bonding methods.

*Graduate Student, Kumamoto University
Table 1 Physical properties of the SiC.

\begin{tabular}{ccc}
\hline $\begin{array}{c}\text { Coefficient of thermal } \\
\text { expansion } \\
\left(\times 10^{-6} \mathrm{~K}^{-1}(\text { at } 1073 \mathrm{~K})\right)\end{array}$ & $\begin{array}{c}\text { Thermal } \\
\text { conductivity } \\
(\mathrm{W} / \mathrm{m} \cdot \mathrm{K} \text { (at R.T. }))\end{array}$ & $\begin{array}{c}\text { Specific resistance } \\
\left(\Omega \mathrm{m} \times 10^{-2}(\text { at R.T. })\right)\end{array}$ \\
\hline 4 & 194 & 0.01 \\
\hline
\end{tabular}

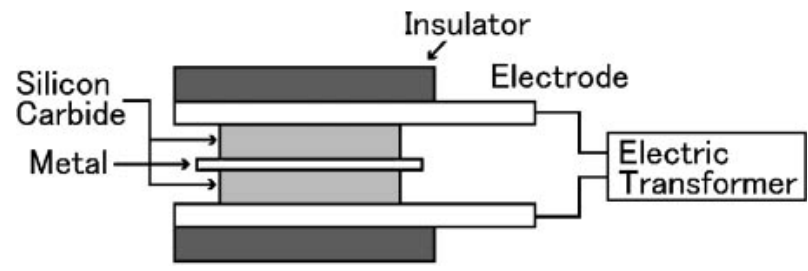

Fig. 1 Schematic illustration of resistance welder of SiC.

\section{Experimental}

Polycrystalline 3C-SiC were used for resistance welding. The physical properties of this $\mathrm{SiC}$ are shown in Table 1 . The welded metals were Ag-27.4 mass\%-4.9 mass\% Ti alloy foil and $\mathrm{Al}$ foil. The thicknesses of the $\mathrm{Ag}-\mathrm{Cu}-\mathrm{Ti}$ alloy foil and $\mathrm{Al}$ foil were $250 \mu \mathrm{m}$ and $12 \mu \mathrm{m}$, respectively. The $\mathrm{SiC}$ were cut into plates $(2 \mathrm{~mm} \times 2 \mathrm{~mm} \times 1 \mathrm{~mm})$ with a low-speed saw and its surface was cleaned with ethanol. The surfaces of the $\mathrm{Ag}-\mathrm{Cu}-\mathrm{Ti}$ alloy foil and $\mathrm{Al}$ foil were ground by buffing before welding. Figure 1 shows a schematic illustration of the resistance welder. The $\mathrm{Ag}-\mathrm{Cu}-\mathrm{Ti}$ alloy foil or $\mathrm{Al}$ foil was placed between two $\mathrm{SiC}$ plates. An alternating current in the range of $25 \sim 50 \mathrm{~A}$ was passed through the $\mathrm{SiC}$ plates for about $0.3 \sim 25 \mathrm{~s}$. The plates were heated to $873 \sim 2473 \mathrm{~K}$ with Joule heat according to the current variation. The temperature of the $\mathrm{SiC}$ was measured using a thermocouple placed on the $\mathrm{SiC}$ plate. The bonded specimen was sliced perpendicular to the interface, followed by mechanical polishing and thinning using an $\mathrm{Ar}^{+}$-ion beam at an accelerating voltage of $3 \mathrm{keV}$ in preparation for transmission electron microscopy. The microstructure of the bonded specimen was observed using a HRTEM (JEM-2000FX, JEOL, Japan) at an accelerating 


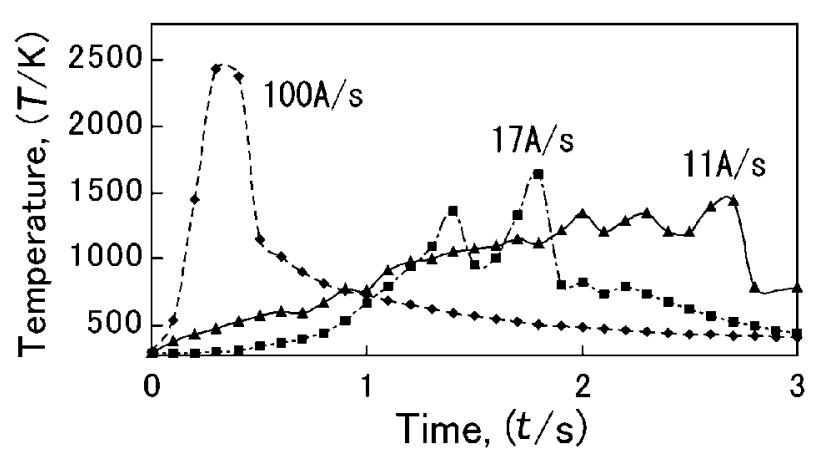

Fig. 2 Relation between welding temperature and the rate of welding current rise of $\mathrm{SiC} / \mathrm{Ag}-\mathrm{Cu}-\mathrm{Ti}$ alloy.

voltage of $200 \mathrm{kV}$. The element distribution around the interface was identified by energy-dispersive X-ray spectroscopy (EDS) equipped with a HRTEM (TECNAI F20, Philips, Netherlands).

\section{Results and Discussion}

\subsection{Thermal behavior of $\mathrm{SiC}$ during resistance welding}

First, we clarified the relationship between SiC temperature and welding current during resistance welding. In this experiment, welding current was increased from 0 to $30 \mathrm{~A}$ at a constant rate, and then turned off immediately upon reaching $30 \mathrm{~A}$. Figure 2 shows the relationship between the temperature variation and the rate of welding current rise up to $30 \mathrm{~A}$. Figure 2 shows that the $\mathrm{SiC}$ plate temperature depends on the rate of welding current rise, and that, as the rate of welding current rise increases, the maximum temperature of the $\mathrm{SiC}$ plates increases. In the $\mathrm{SiC} / \mathrm{Ag}-\mathrm{Cu}-\mathrm{Ti}$ alloy system, a maximum temperature of approximately $2473 \mathrm{~K}$ was obtained within $0.3 \mathrm{~s}$. The maximum temperature showed no further increase even when welding current was kept at $30 \mathrm{~A}$ for $3 \sim 5 \mathrm{~s}$ after the constant welding current rise.

In the following experiments, we fixed the welding current but changed the rate of welding current rise to a fixed welding current to obtain various kinds of welded specimen.

\subsection{Resistance welding of $\mathrm{SiC} / \mathrm{Al}$}

Figure 3 shows a bright field image around the welded interface between $\mathrm{SiC}$ and $\mathrm{Al}$ for a welding current of $50 \mathrm{~A}$. The rate of welding current rise was $100 \mathrm{~A} / \mathrm{s}$. Under this welding condition, the maximum welding temperature was approximately $2473 \mathrm{~K}$ and the entire welding process took $0.5 \mathrm{~s}$. Among specimens welded under various welding conditions, this specimen had a sufficiently high strength for processing into a thin film for HRTEM observation.

In Fig. 3, black contrast regions are observed adjacent to $\mathrm{SiC}$ and the interface between $\mathrm{SiC}$ and the regions show step morphology. At the interface, the $\{111\}$ plane of $\mathrm{SiC}$ tends to be parallel to the interface. Figure 4 shows a low magnification lattice image of the region around the interface of $\mathrm{SiC} /$ $\mathrm{Al}$. Electron diffraction patterns and lattice images suggested that $\mathrm{Al}_{4} \mathrm{C}_{3}, \mathrm{Al}$ and an amorphous phase formed directly adjacent to $\mathrm{SiC}$. Broken lines in Fig. 4 indicate the interfaces among $\mathrm{Al}_{4} \mathrm{C}_{3}, \mathrm{Al}$ and the amorphous phase determined from the lattice image. White contrasts parallel to the interface is

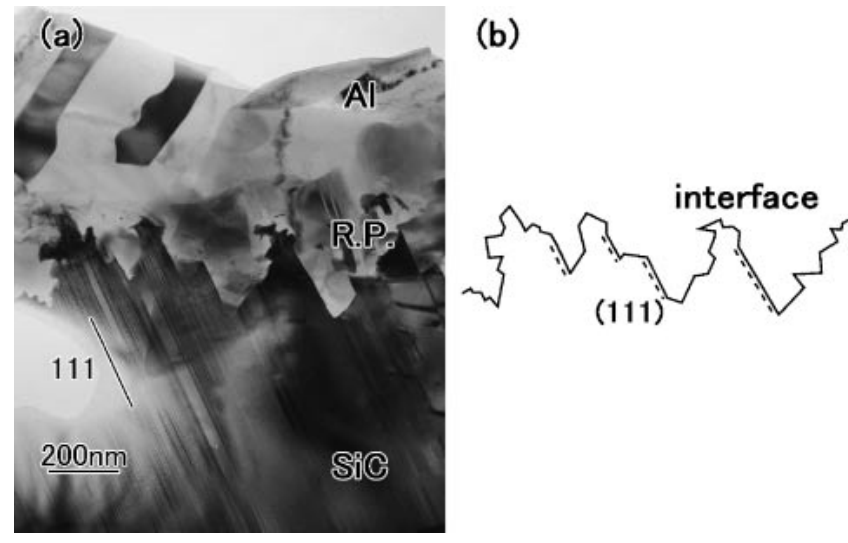

Fig. 3 (a) Bright field image of the welded interface between $\mathrm{Al}$ and $\mathrm{SiC}$. R.P. indicate the reaction phase. (b) Schematic image of SiC/R.P. interface in (a). Several parts of the interface indicated by broken lines tend to parallel to the (111) plane of SiC.

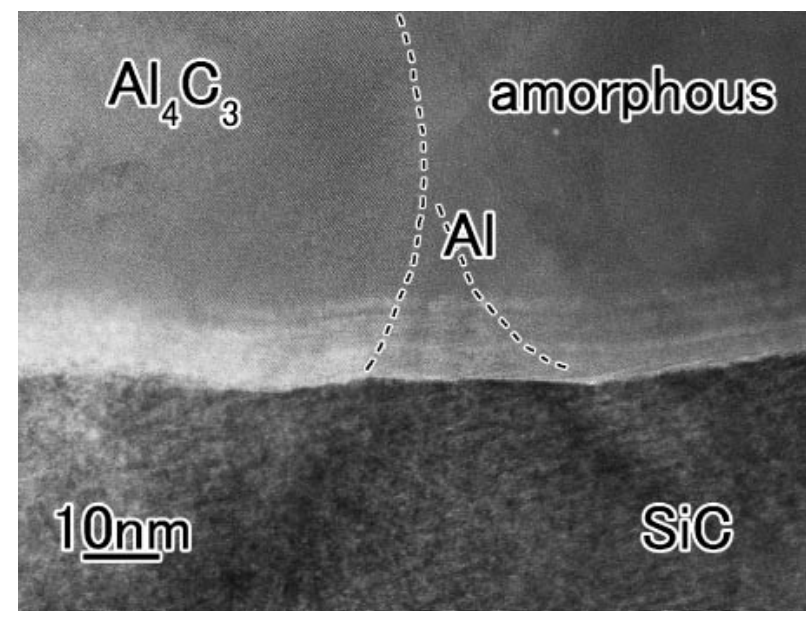

Fig. 4 Magnified image of the $\mathrm{SiC} /$ reaction phase interface. $\mathrm{Al}_{4} \mathrm{C}_{3}, \mathrm{Al}$ and amorphous phase was observed at the interface.

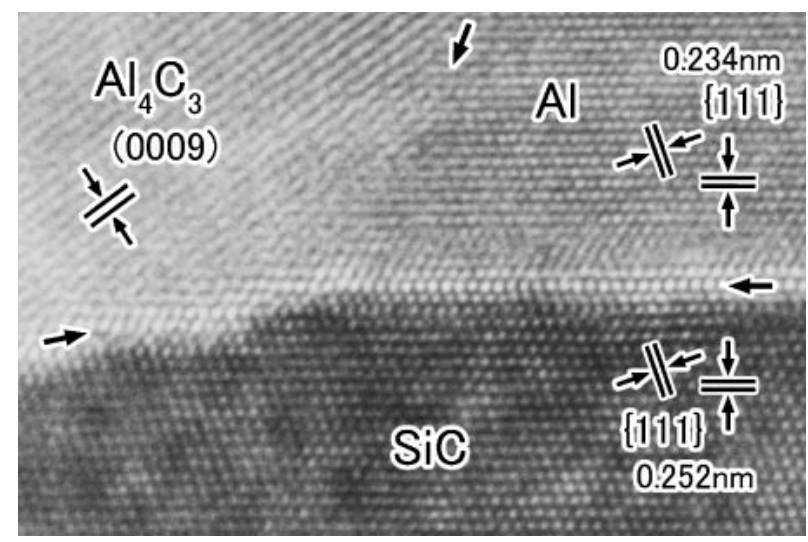

Fig. 5 High-resolution image of the $\mathrm{SiC} /$ reaction phase interface. Arrows denote the $\mathrm{Al}_{4} \mathrm{C}_{3} / \mathrm{Al} / \mathrm{SiC}$ interfaces. Aluminum forms on the (111) plane of the $\mathrm{SiC}$ with an orientation relationship of (111)SiC // (111)Al, $[1 \overline{1} 0] \mathrm{SiC} / /[1 \overline{1} 0] \mathrm{Al}$.

an optical artifact and do not relate to the interface structure. Figure 5 shows a high-resolution image of the region around the triple point of $\mathrm{Al}_{4} \mathrm{C}_{3}, \mathrm{Al}$ and $\mathrm{SiC}$. The morphology of the 


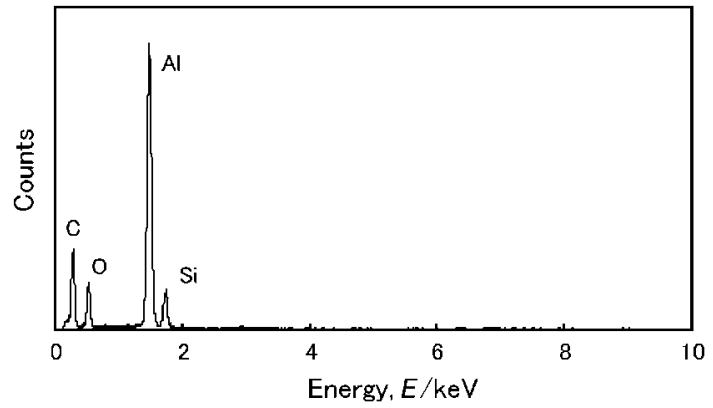

Fig. 6 EDS spectra obtained from the amorphous phase at the $\mathrm{SiC} / \mathrm{Al}$ interface.

$\mathrm{SiC} / \mathrm{Al}$ interface is flat at the atomic level. Aluminum forms on the (111) plane of the $\mathrm{SiC}$ with an orientation relationship

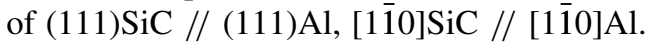

The (111) plane of the SiC parallel to the interface is a polar plane. In the literature, when a molten alloy reacts with the basal plane of $6 \mathrm{H}-\mathrm{SiC}$ which is the same structure of the (111) plane of the 3C-SiC, 6H-SiC tends to dissociate along the basal plane, which is a polar plane formed by either $\mathrm{C}$ or $\mathrm{Si}$ atoms. ${ }^{4,5)}$ After the dissociation of $\mathrm{SiC}$, reaction phases form from the molten alloy. Our observations suggest that SiC dissociated along the (111) plane, which is the polar plane of 3C-SiC, and $\mathrm{Al}$ formed on the (111) plane with a crystallographic orientation relationship.

An amorphous phase, shown in Fig. 4, occasionally formed at the interface. To clarify amorphous-phase formation, EDS spectra were obtained. Figure 6 shows typical EDS spectra, which indicate that the amorphous phase adjacent to the $\mathrm{SiC}$ consists of $\mathrm{Al}, \mathrm{Si}, \mathrm{C}$ and $\mathrm{O}$. This kind of amorphous phase is also observed at the $\mathrm{Al} / \mathrm{SiC}$ diffusion-bonded interface. ${ }^{1)}$ Formation of the amorphous phase was explained to be a result of the diffusion of $\mathrm{Si}, \mathrm{C}$ and $\mathrm{Al}$ to amorphous silica, which was present on the SiC surface before bonding. However, at the interface bonded with molten $\mathrm{Al}$, no amorphous phase was observed., ${ }^{2,3)}$ In the present welding technique, the welding time and temperature were extremely short $(0.5 \mathrm{~s})$ and high $(2473 \mathrm{~K})$, respectively, in contrast to those in the previous experiments. Thus, the freezing of oxygen-containing molten $\mathrm{Al}$ alloy which was produced by the dissolution of $\mathrm{SiO}_{2}$ was considered to be associated with the amorphous phase formation.

The formation of $\mathrm{Al}_{4} \mathrm{C}_{3}$ and $\mathrm{Al}$ phases adjacent to the $\mathrm{SiC}$ was explained taking thermodynamics into consideration. ${ }^{7,8)}$ Thermodynamic calculation gives the following reaction equation between $\mathrm{SiC}$ and $\mathrm{Al}$.

$$
3 \mathrm{SiC}(\mathrm{s})+4 \mathrm{Al}(\mathrm{l})=\mathrm{Al}_{4} \mathrm{C}_{3}+3[\mathrm{Si}]
$$

Here, [Si] represents $\mathrm{Si}$ in the Al-Si liquid solution. In this experiment, the short welding time prevented Si diffusion, and the local Si concentration near the interface increased. The high $\mathrm{Si}$ concentration is considered to suppress continuous $\mathrm{Al}_{4} \mathrm{C}_{3}$ layer formation.

At the present stage of our investigation, temperature dependence of the reaction phase formation in the present system was not clarified. The detailed analysis of the formation process of the reaction phase will be done in the future.
Table 2 Thickness of the reaction phases in the $\mathrm{SiC} / \mathrm{Ag}-\mathrm{Cu}-\mathrm{Ti}$ alloy.

\begin{tabular}{cccc}
\hline Specimen & $\begin{array}{c}\text { Ratio of current } \\
\text { rise (A/s) }\end{array}$ & $\begin{array}{c}\text { Maximum } \\
\text { temperature (K) }\end{array}$ & $\begin{array}{c}\text { Reaction layer } \\
\text { thickness (nm) }\end{array}$ \\
\hline 1 & 1.2 & 933 & 222 \\
2 & 11 & 1434 & 187 \\
3 & 18 & 1645 & 14 \\
4 & 100 & 2473 & 407 \\
\hline
\end{tabular}

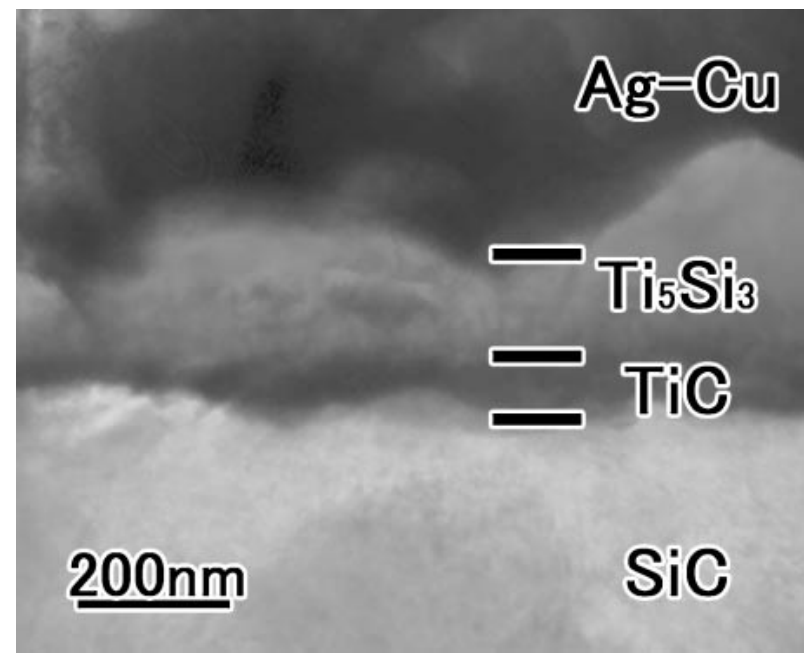

Fig. 7 Bright field image of the reaction phases produced at the $\mathrm{SiC} / \mathrm{Ag}$ $\mathrm{Cu}$-Ti welded interface in specimen 1.

\subsection{Resistance welding of $\mathrm{SiC} / \mathrm{Ag}-\mathrm{Cu}-\mathrm{Ti}$ alloy}

Table 2 shows the welding conditions in the $\mathrm{SiC} / \mathrm{Ag}-\mathrm{Cu}-$ $\mathrm{Ti}$ alloy system. The rate of welding current rise to a welding current of $30 \mathrm{~A}$ varies from $1.2 \mathrm{~A} / \mathrm{s}$ to $100 \mathrm{~A} / \mathrm{s}$. Under these welding conditions, a maximum welding temperature in the range from $933 \mathrm{~K}$ to $2473 \mathrm{~K}$ is obtained. Figure 7 shows a bright field image of the region around the interface of the $\mathrm{SiC} / \mathrm{Ag}-\mathrm{Cu}-\mathrm{Ti}$ alloy of specimen 1 in Table 2. Two layers of the reaction phases are observed. Electron diffraction patterns indicated that the upper reaction phase was $\mathrm{Ti}_{5} \mathrm{Si}_{3}$, and the lower one was $\mathrm{TiC}$.

The average thicknesses of the reaction phases differed among specimens 1, 2 and 4, as shown in Table 2, however, the morphologies of these specimens were similar to that of specimen 1 shown in Fig. 7.

Figure 8 shows a bright field image of the interface of the $\mathrm{SiC} / \mathrm{Ag}-\mathrm{Cu}-\mathrm{Ti}$ alloy of specimen 3. In contrast to specimens 1,2 , and 4 , reaction phases hardly observed. Figure 9 shows the high-resolution image of the region around the interface of specimen 3. At the interface, a thin reaction phase is observed adjacent to the $\mathrm{SiC}$. The lattice image of the reaction phase suggests that the layer consisted of $\mathrm{TiC}$ and $\mathrm{Ti}_{5} \mathrm{Si}_{3}$ nanoparticles. In some regions, Ag directly connects with the SiC. The average thickness of the layer was about $14 \mathrm{~nm}$.

The morphology of the $\mathrm{SiC}$ crystal was unchanged after welding for specimens $1-4$.

There have been several extensive studies of the kinds of reaction phase in the $\mathrm{SiC} / \mathrm{Ag}-\mathrm{Cu}-\mathrm{Ti}$ alloy system. ${ }^{9)} \mathrm{In} \mathrm{SiC} /$ Ag-Cu-Ti alloy brazing, $\mathrm{TiC}$ and $\mathrm{Ti}_{5} \mathrm{Si}_{3}$ are produced as 


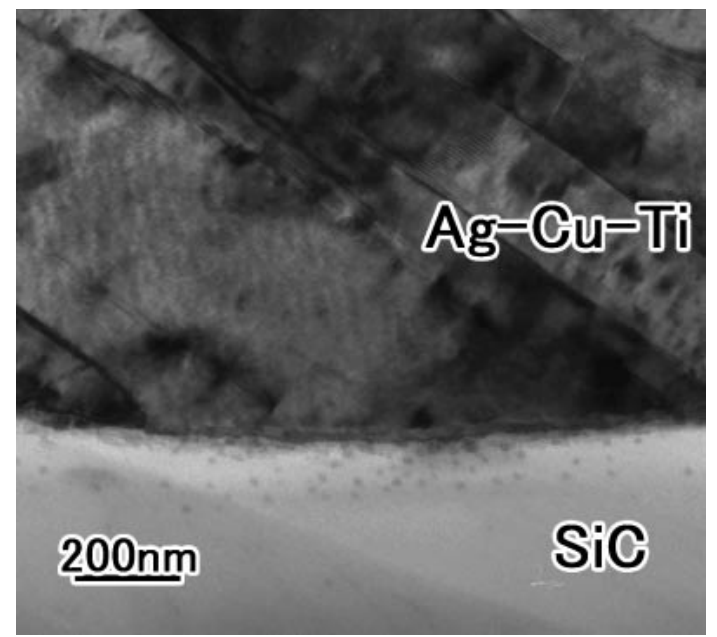

Fig. 8 Bright field image of the welded interface of $\mathrm{SiC} / \mathrm{Ag}-\mathrm{Cu}-\mathrm{Ti}$ in specimen 3.

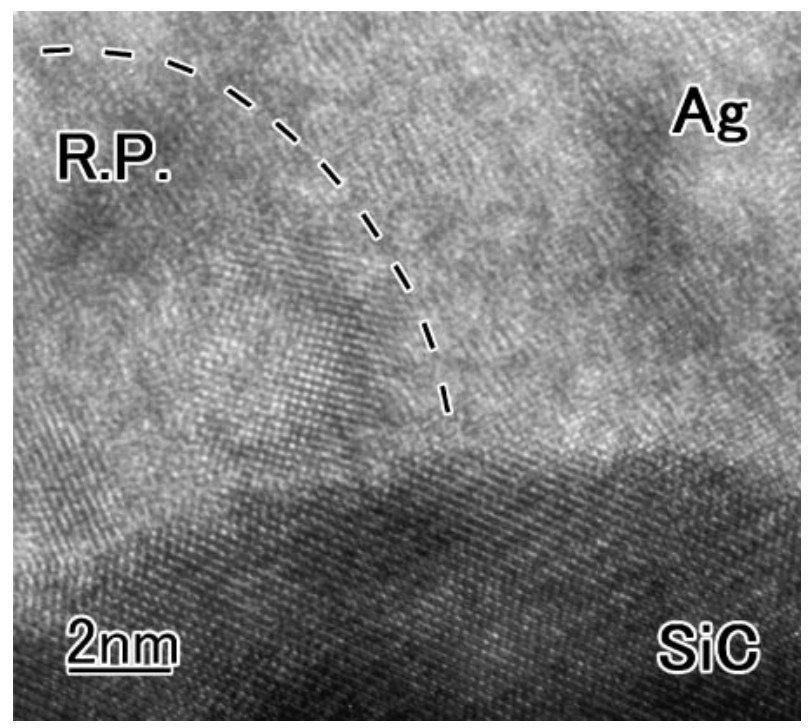

Fig. 9 High-resolution image of the welded interface of $\mathrm{SiC} / \mathrm{Ag}-\mathrm{Cu}-\mathrm{Ti}$ in specimen 3 .

reaction phases. HRTEM observation has revealed that the $\mathrm{TiC}$ layer initially forms adjacent to the $\mathrm{SiC}$ following $\mathrm{Ti}_{5} \mathrm{Si}_{3}$ formation. ${ }^{10)}$ This double layer formation consisting of an outer $\mathrm{Ti}_{5} \mathrm{Si}_{3}$ layer and inner $\mathrm{TiC}$ layer was also confirmed by direct in-situ HRTEM observation. ${ }^{6}$ ) The kinds of reaction phase formed in the previous experiments are in accordance with the present results.

The relationship between the thickness of the reaction phases and the rate of welding current rise, shown in Table 2, was discussed as follows. Under certain welding conditions such as those for specimen 3 , the thicknesses of the reaction layers were minimum. The thickness variation was considered to be associated with the quantity of heat and maximum temperature. As the rate of welding current rise increases, the quantity of heat during welding decreases, because of the shorter welding time. In contrast, maximum welding temperature, which affects the growth rate of the reaction phases, increases. These conflicting behaviors regarding the growth of the reaction phases between the quantity of heat and the maximum temperature were considered to determine the welding conditions that lead to the minimum thickness of the reaction layer.

\section{Conclusions}

Resistance welding was applied to the bonding of $\mathrm{SiC}$ to $\mathrm{Al}$ or Ag-Cu-Ti alloy. The interface morphology variation dependence on welding conditions was revealed using HRTEM and the following results were obtained.

(1) Welding temperature depended on the rate of welding current rise. In $\mathrm{SiC} / \mathrm{Ag}-\mathrm{Cu}-\mathrm{Ti}$ alloy, a maximum temperature of approximately $2473 \mathrm{~K}$ was obtained within $0.3 \mathrm{~s}$.

(2) In the $\mathrm{SiC} / \mathrm{Al}$ system, $\mathrm{Al}_{4} \mathrm{C}_{3}, \mathrm{Al}$ and an amorphous phase were formed adjacent to $\mathrm{SiC}$. The $\mathrm{SiC} / \mathrm{Al}$ interface was flat at the atomic level. Aluminum formed on the (111) plane of $\mathrm{SiC}$ with an orientation relation-

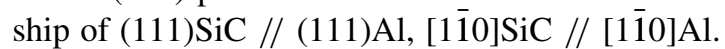

(3) In the $\mathrm{SiC} / \mathrm{Ag}-\mathrm{Cu}-\mathrm{Ti}$ system, the reaction phases $\mathrm{TiC}$ and $\mathrm{Ti}_{5} \mathrm{Si}_{3}$ were formed at the interface. Depending on the rate of welding current rise, the thickness of the reaction phases varied. Under specific welding conditions, Ag directly formed adjacent to $\mathrm{SiC}$ without reaction phases.

\section{Acknowledgments}

This study is partly supported by a Grant-in-Aid for Scientific Research on Priority Area (c) (Grant No. 17560619) from the Ministry of Education, Culture, Sports, Science and Technology of Japan.

\section{REFERENCES}

1) P. L. Ratnaparkhi and J. M. Howe: Acta Metal. Mater. 42 (1994) 811823.

2) T. Yano, S. Kato and T. Iseki: J. Am. Ceram. Soc. 75 (1992) 580-586.

3) S. D. Peteves, et al.: J. Mater. Sci. 25 (1990) 3765-3772.

4) C. Iwamoto and S.-I. Tanaka: Acta. Mater. 46 (1998) 2381-2386.

5) C. Iwamoto, H. Ichinose and S.-I. Tanaka: Philos. Mag. A. 79 (1999) 85-95.

6) C. Iwamoto, K. Matsunaga, T. Yamamoto and Y. Ikuhara: Nanotechnology 15 (2004) 398-401.

7) T. Iseki, T. Kameda and T. Maruyama: J. Mater. Sci. 19 (1984) 16921698.

8) T. Iseki, T. Kameda and T. Maruyama: Pros. Br. Ceram. Soc. 34 (1984) 241-248.

9) H.-K. Lee, S.-H. Hwang and J. T. Lee: J. Mater. Sci. 28 (1993) 1765.

10) M. Nomura, T. Ichimori, C. Iwamoto and S.-I. Tanaka: J. Mater. Sci. 35 (2000) 3953-3958. 